\title{
Theoretical Rotordynamic Coefficients of Labyrinth Gas Seals: a Parametric Study on a Bulk Model
}

\author{
PAOLA FORTE* and FABIO LATINI \\ Dipartimento di Costruzioni Meccaniche e Nucleari, Faculty of Engineering, University of Pisa, Via Diotisalvi 2, 56126 Pisa, Italy
}

(Received May 1998; In final form June 1998)

\begin{abstract}
To date, available mathematical bulk models for the determination of linearized rotordynamic coefficients of labyrinth gas seals yield results which are not always in good agreement with the experimental ones. The object of this work is to discuss the limits of these models and to point out possible improvements and aspects that need further investigation.

After a study of the steady flow characteristics with an FEM code, a parametric computer program, based on a known two-volume model, has been developed. A perturbation approach has been applied to the governing equations of the bulk model to calculate the stiffness and damping coefficients. Predicted coefficients are compared to the results of an earlier onevolume model.

The model has also been tested with different expressions of the axial velocities in the two volumes and different laws for leakage and shear stress. The theoretical results are compared to the published experimental ones, pointing out the small effect of the various parameters in improving the correlation and the need of more complex models.
\end{abstract}

Keywords: Rotordynamic coefficients, Labyrinth gas seals, Bulk model

Abbreviations: TOS, teeth on stator; TOR, teeth on rotor labyrinth seals

\section{INTRODUCTION}

The knowledge of linearized rotordynamic coefficients of labyrinth gas seals is very important in the design of turbomachinery for determining resonances and investigating the stability of the system.

Unfortunately, to date, published experimental results regard tests carried out at low pressures and available mathematical models, based on bulk quantities, yield results which are not always in good agreement with the experimental ones.

The first one-volume bulk model was proposed by Iwatsubo (1980) and developed by Scharrer (1985). The latter in cooperation with Childs (1986) carried out the most extensive comparison of analytical predictions and experimental results,

\footnotetext{
* Corresponding author. Tel.: +39-50-585 246. Fax: +39-50-585265. E-mail: p.forte $(a)$ ing.unipi.it.
} 
which showed the validity of the model in predicting cross-coupled stiffness and its inadequacy in predicting the other dynamic coefficients. As a matter of fact this coefficient is more important than the others as far as stability is concerned since it affects the destabilizing tangential force. None the less the direct stiffness coefficient may have a non-negligible effect on the global stiffness of the rotor, therefore on its natural frequencies while the damping coefficients affect the stabilizing force. Afterwards, also on the basis of the experimental observation of the peculiar flow in the cavity and CFD calculations by other authors such as Iwatsubo et al. (1982); Rhode and Nail (1992); Rhode et al. (1993); Scharrer (1988) modified the bulk model in a two-volume one. A quite limited comparison of the performance of the two models is reported in Childs and Scharrer (1988). Poorer correlations between theoretical and experimental results were found by Pelletti (as reported by Childs, 1993) at reduced clearances, high speeds and high pressures.

The object of this work is to discuss the limits of bulk models and to point out possible improvements and aspects that need further investigation. To do that, a parametric computer program, based on Scharrer's two-volume model, has been developed. One- and two-volume predicted coefficients are compared in a wider range of cases. Simple modifications of the model are proposed and tested.

\section{CFD STUDY OF CAVITY FLOW IN STEADY CONDITIONS}

The authors first studied the steady characteristics of flow through the seal with two different codes based on FEM and finite volumes. Typical results are presented in Fig. 1. The gas jet expands in the cavity generating a vortex. In most cases the flow is highly turbulent, and only for low mean pressure and low pressure drop there can be partially laminar conditions.

The use of these codes proved quite costly in terms of time and required a clever choice of parameters to have convergence. Therefore the authors abandoned the idea of investigating unsteady conditions with it. Even if CFD codes are useful to understand flow phenomena, they do not seem at present suitable for design purposes.

\section{TWO-VOLUME BULK MODEL}

The experimental and CFD observations of the flow in the labyrinth seal cavity suggest the division of the volume in two parts: one by the rotor, thick as the clearance, filled by the jet, the other being the cavity itself with the recirculation flow.

The model is based on the following assumptions:

(1) the gas is considered ideal and the temperature is constant throughout the seal;
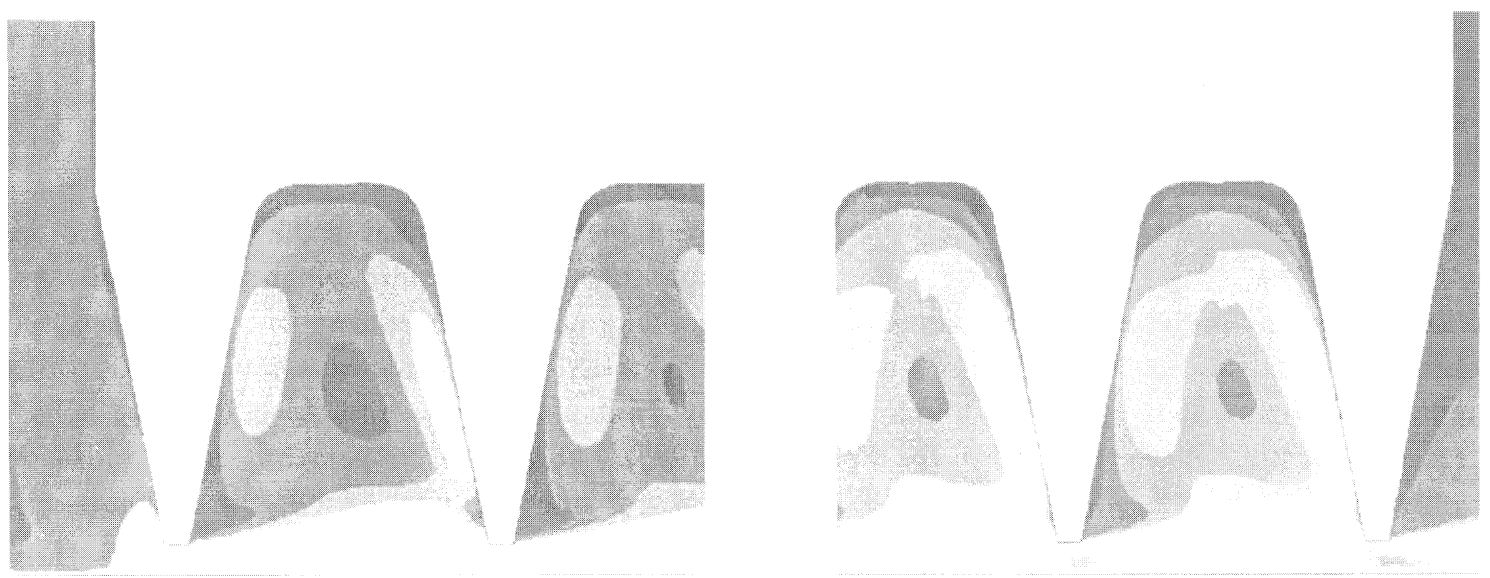

FIGURE 1 Contour plot of total velocities at inlet and outlet of a TOS seal (obtained with FLUENT ${ }^{(R)}$ ) 
(2) pressure variations in the cavity are negligible compared to the pressure drop across the restriction;

(3) frequencies of acoustic resonances are much higher than that corresponding to the rotor speed;

(4) rotor eccentricity is small compared to the clearance;

(5) friction forces on the rotor are small compared to those due to pressure variation;

(6) all significant quantities are constant inside each volume, while pressure, assumed constant in each cavity, is the same for the two volumes.

As done by Iwatsubo et al. (1982) the mass continuity equation and the circumferential momentum equation can be stated for the two volumes. Figure 2 shows an explanatory diagram of the forces acting on the two volumes. The axial momentum equation may be substituted by an empirical equation proposed by Neumann (1964) to express the gas leakage through the restricted section. The leakage formula yields the mean axial velocity in volume one for each cavity. It is a local definition since it is a function of local clearance

$$
\dot{m}_{i}=\mu_{0} \mu_{i} H\left[\left(P_{i-1}^{2}-P_{i}^{2}\right) / R T\right]^{1 / 2}=\rho_{i} W_{1 i} H
$$

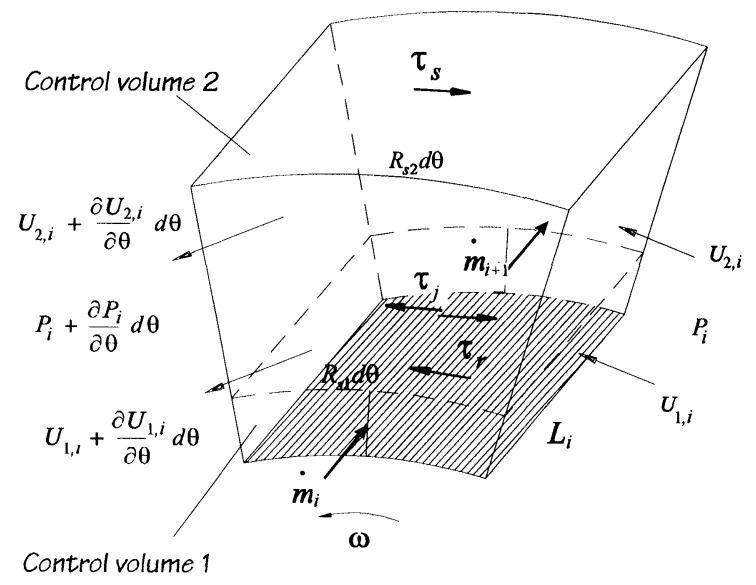

FIGURE 2 Two-control-volume model. where $\mu_{0}$ is the kinetic energy carryover coefficient and $\mu_{i}$ the flow coefficient,

$$
\begin{aligned}
\mu_{i} & =\pi /\left(\pi+2-5 \beta_{i}+2 \beta_{i}^{2}\right), \\
\beta_{i} & =\left(P_{i} / P_{i-1}\right)^{(\gamma-1) / \gamma}-1 .
\end{aligned}
$$

Different expressions have been proposed for $\mu_{0}$. It has been defined as a constant value dependent on geometric quantities, such as the number of teeth ND, clearance $\mathrm{Cr}$ and cavity length $L_{i}$,

$$
\begin{aligned}
\mu_{0} & =\{\mathrm{ND} /[(1-\alpha) \mathrm{ND}+\alpha]\}^{1 / 2}, \\
\alpha & =1-\left(1+16.6 \mathrm{Cr} / L_{i}\right)^{-2},
\end{aligned}
$$

or as function of the local clearance $H$,

$$
\begin{aligned}
\mu_{0} & =(1-\alpha)^{-1 / 2}, \\
\alpha & =8.52 H /\left[\left(L_{i}-\operatorname{td}_{i}\right)+7.23 H\right] .
\end{aligned}
$$

In Section 5 the differences in the results related to the two different approaches will be shown.

Extending the results of studies on jets in contact with co-flowing and cross-flowing streams yields a relation between the velocities of the two streams. In steady conditions Scharrer obtained that the ratio between boundary layer thickness and mixing thickness $b$ equals 0.5 and that the ratio between average axial velocities in the two volumes is constant and equal to 0.206 . As regards the mixing length parameter, while Wyssman et al. (1984) had obtained a function of geometric quantities but had neglected the recirculating velocities, Scharrer, on the basis of CFD results concluded that the mixing length ratio $l / b$ was relatively constant $(0.275$ for TOR seals, 0.210 for TOS). So he proposed the following expression for the total free shear stress

$$
\tau_{j}=\lambda \cdot \rho\left|\vec{V}_{2}-\vec{V}_{1}\right|\left(\vec{V}_{2}-\vec{V}_{1}\right)
$$

where $V$ is the total velocity and $\lambda$ is a coefficient equal to 0.142 for TOR seals, 0.083 for TOS.

As regards the rotor and the stator shear stresses they are found applying Blasius' equation. 
For TOS seals

$\tau_{\mathrm{r}}=\left(\rho_{i} / 2\right) n \operatorname{Re}_{\mathrm{r}}^{m}\left[\left(\omega r-U_{1}\right)^{2}+W_{1}^{2}\right]^{1 / 2}\left(\omega r-U_{1}\right)$,

$\tau_{\mathrm{s}}=\left(\rho_{i} / 2\right) n \operatorname{Re}_{\mathrm{s}}^{m}\left(U_{2}^{2}+W_{2}^{2}\right)^{1 / 2} U_{2}$,

where $U$ and $W$ are respectively the circumferential and axial velocities, $\omega r$ is the rotor speed, and $n$ and $m$ empirically determined coefficients $(n=0.0187$, $m=-0.33$ ). Similar expressions can be written for TOR.

Radial journal growth with speed can easily be accounted for.

By substitution the above equations can be reduced to three, the fundamental unknown variables being pressure in the cavity and average circumferential velocities in the two volumes.

\section{THE ROTORDYNAMIC COEFFICIENTS}

The bulk model yields a non-linear system of three equations for each seal cavity. As it is well known the seal reaction to the rotor motion about the centered position can be represented by

$$
-\left(\begin{array}{c}
F_{x} \\
F_{y}
\end{array}\right)=\left[\begin{array}{cc}
K & k \\
-k & K
\end{array}\right]\left(\begin{array}{c}
X \\
Y
\end{array}\right)+\left[\begin{array}{cc}
C & c \\
-c & C
\end{array}\right]\left(\begin{array}{c}
\dot{X} \\
\dot{Y}
\end{array}\right) .
$$

In order to calculate the direct and cross-coupled stiffness and damping coefficients, a small elliptical orbit of the rotor is assumed. Therefore local clearance is perturbed assuming the eccentricity ratio $\varepsilon$ as the perturbation parameter,

$$
H=H_{0}+\varepsilon H_{1}
$$

and consequently pressure and circumferential velocities are perturbed as well. The governing equations of the bulk model are then expanded in the perturbation variables. The solution of the zeroth-order equations yields the values of the fundamental variables for the rotor in the centered steady position. Because of non-linearity, the calculation must be iterative first assuming flow critical conditions in the last restriction, thus calculating leakage and pressures in the cavities from the last to first one and checking the supply pressure value. If calculated supply pressure is lower than the real one the flow is not critical, therefore the leakage is assigned and up-dated until pressure boundary conditions are satisfied.

Having assumed an elliptical orbit the perturbations of clearance, pressure and circumferential velocities can be expressed in terms of sine and cosine functions of the angular coordinate $\theta$ and of the shaft rotation $\omega t$. Substituting in the first-order equations and grouping similar terms of sines and cosines, yield a system of twelve linear equations for each cavity. The lengthy and tedious work of determining these expressions was eased by Mathematica ${ }^{\circledR}$. The system of equations has a tridiagonal coefficient matrix and can be solved numerically by a direct method. The authors used the quite efficient algorithm of Thomas.

\section{COMPARISON WITH PUBLISHED THEORETICAL AND EXPERIMENTAL RESULTS}

A computer program based on the theoretical model described above was developed and tested. A comparison with Scharrer's two-volume results could be only qualitative because the boundary and operating conditions used for his calculations were not completely known. Moreover some discrepancies, probably due to misprints, were noticed in Scharrer's paper which hindered the authors in using directly his formulas. Anyhow the trends of predicted coefficients were similar.

The program was also tested comparing its results with those of the one-volume model and with the only available experimental results, obtained on the test-rig of the Texas A\&M University, both taken from Scharrer's report (1985). The tested seal has 16 teeth, a radius of $72.5 \mathrm{~mm}$, a length of $50.8 \mathrm{~mm}$ and a clearance of $0.406 \mathrm{~mm}$.

Figure 3 shows leakage as function of supply pressure while Fig. 4 shows a typical diagram of pressure in the seal. The introduction of the 


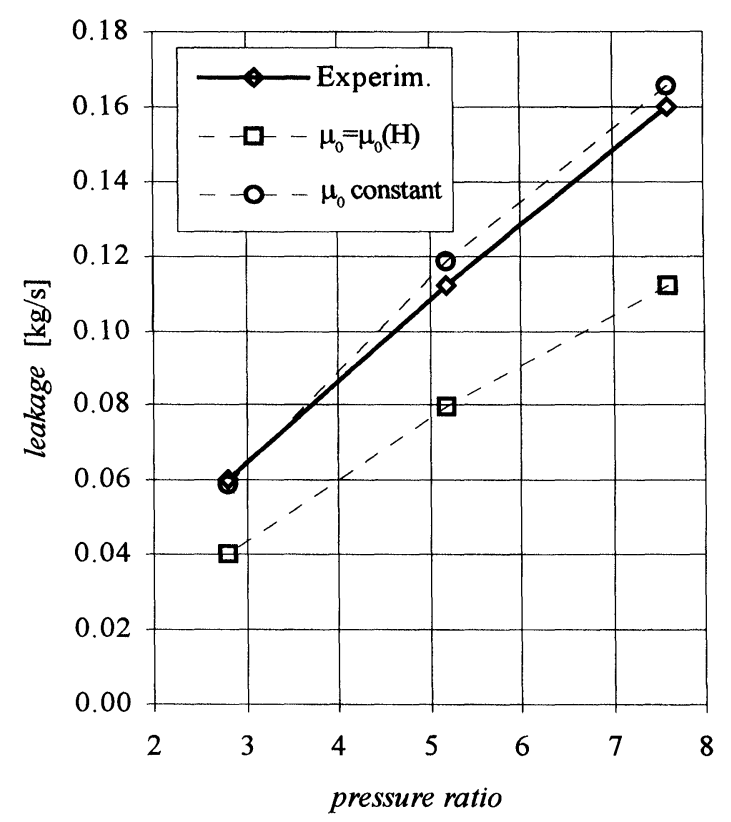

FIGURE 3 Leakage in TOS seal $\left(3000 \mathrm{rpm}, u_{0}=4.4\right)$.

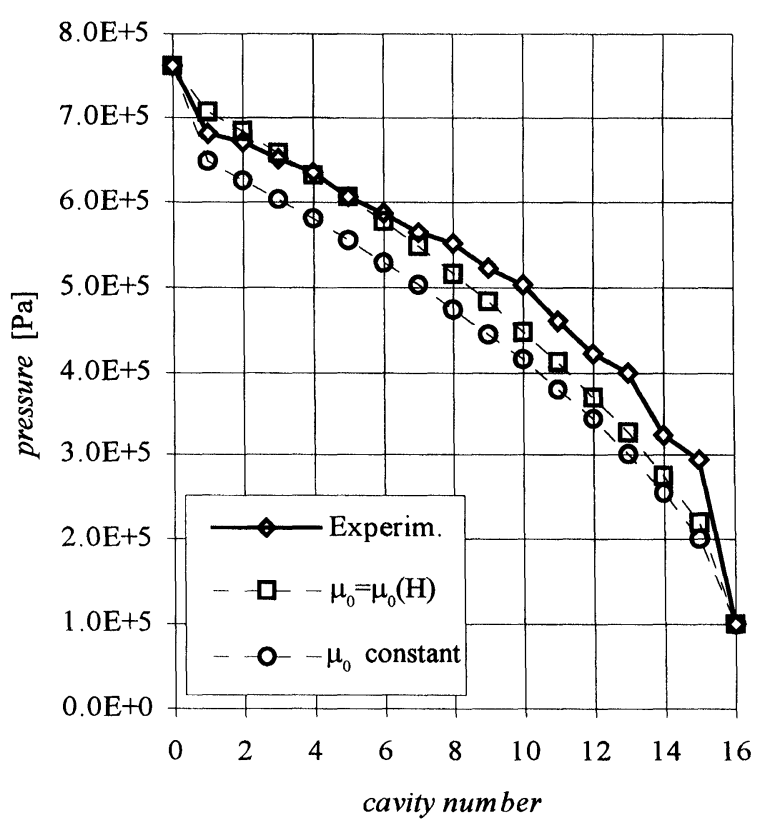

FIGURE 4 Pressure in TOS seal $\left(8000 \mathrm{rpm}, u_{0}=1.65\right)$

dependence of $\mu_{0}$ on $H$ does not appear to be appropriate for calculating leakage since the relative error is about $40 \%$ while constant $\mu_{0}$ determines an error of $5-10 \%$. On the other hand the

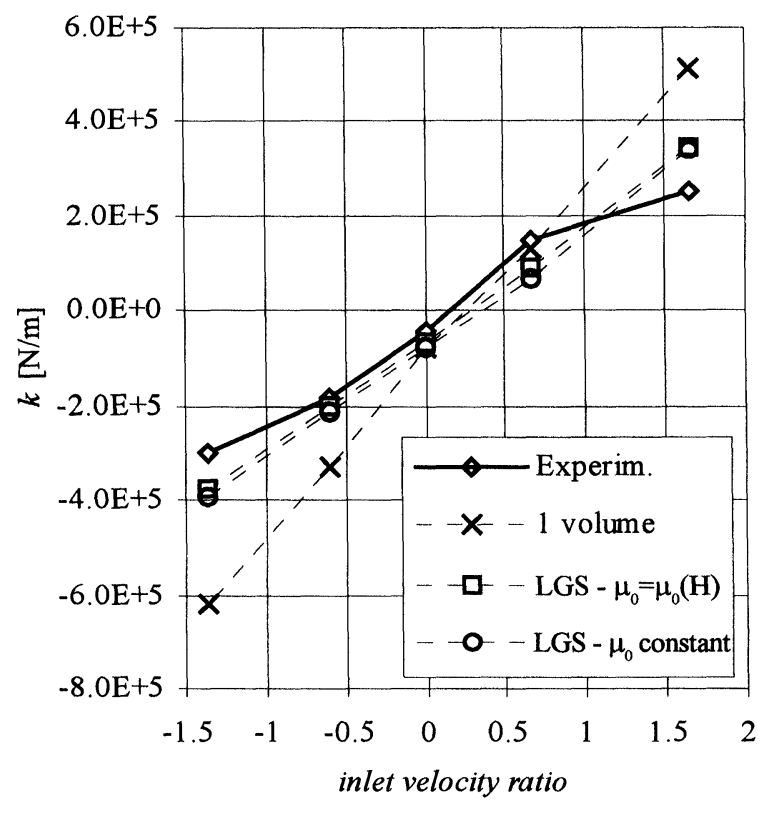

FIGURE 5 Cross-coupled stiffness for TOS seal (supply pressure $0.822 \mathrm{MPa}, 8000 \mathrm{rpm}$ ).

former expression yields better results for pressure as the latter one produces an overestimation of the pressure drop in the first cavity.

Figures 5 and 6 show theoretical and experimental cross-coupled stiffness coefficients for a TOS seal. The main operating quantities are inlet velocity ratio $u_{0}$ (inlet tangential velocity/rotor speed), supply pressure and rotor speed. It is evident that theory does a rather good job in predicting cross-coupled stiffness coefficients though the error increases as the inlet velocity ratio increases. Moreover the two volumes represent a better approximation while the $H$ dependent $\mu_{0}$ does not seem to produce significant improvements. Theoretical models are slightly sensitive to rotor speed in agreement with experimental results. On the contrary supply pressure has a significant influence on cross-coupled stiffness and the error in prediction increases with pressure but the trend is predicted better by the two-volume model.

Figures 7 and 8 show theoretical and experimental direct stiffness coefficients for a TOS seal. Theory predicts a high dependence on inlet velocity 


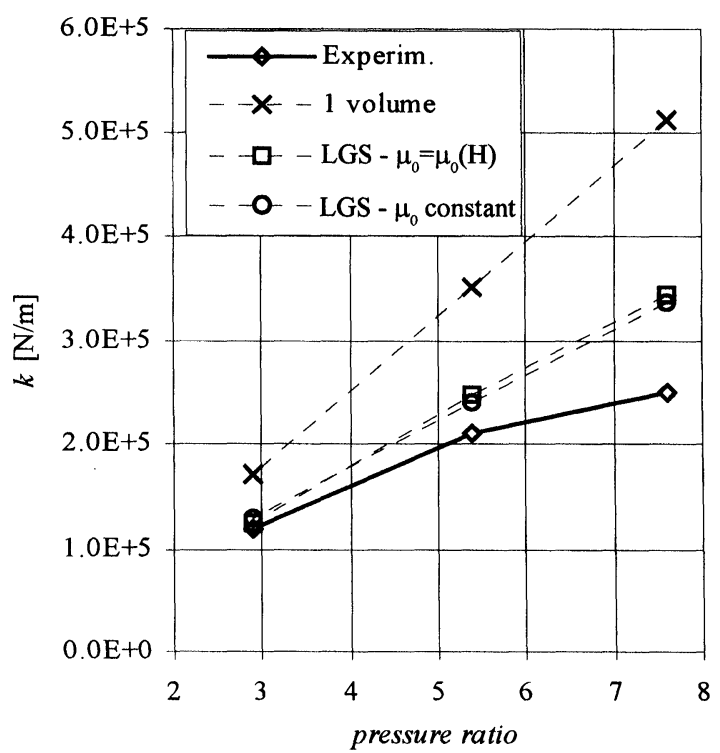

FIGURE 6 Cross-coupled stiffness for TOS seal $(8000 \mathrm{rpm}$, $\left.u_{0}=1.65\right)$.

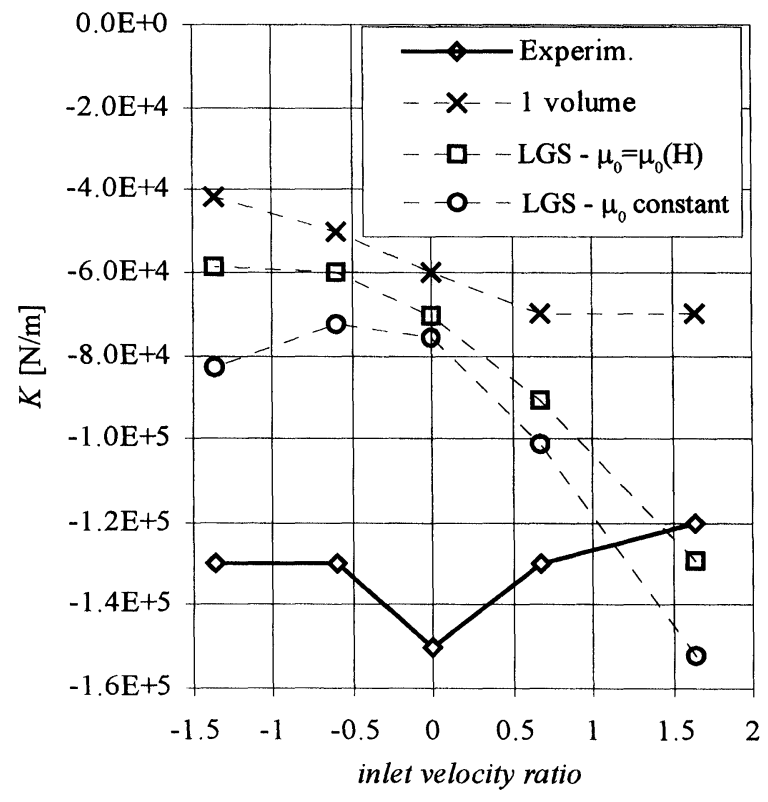

FIGURE 7 Direct stiffness for TOS seal (supply pressure $0.822 \mathrm{MPa}, 8000 \mathrm{rpm}$ )

ratio, higher for the two-volume model, which is not confirmed experimentally, while it predicts the right trend for the dependence on supply pressure. The dependence on rotor speed, not presented here,

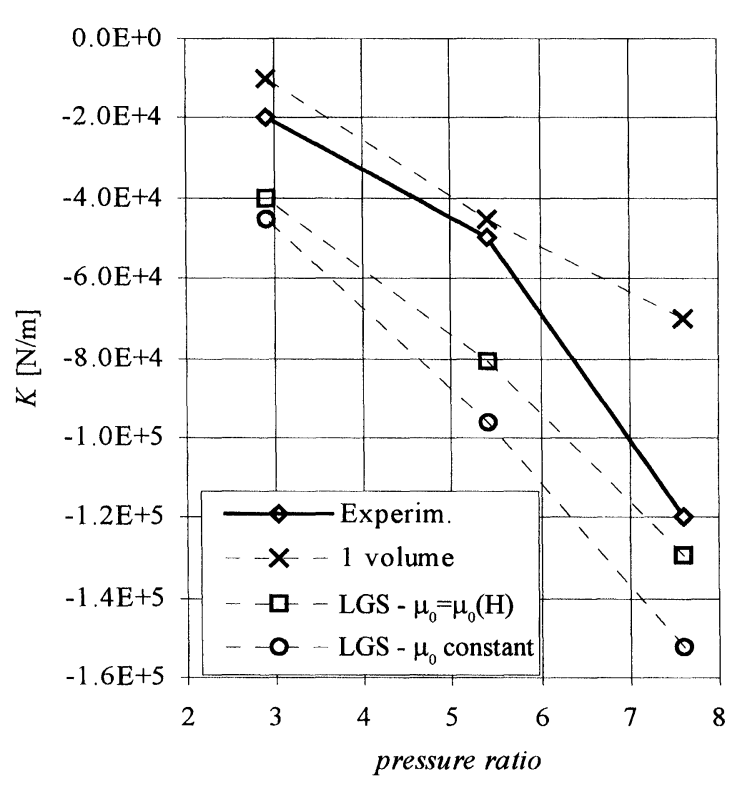

FIGURE 8 Direct stiffness for TOS seal $(8000 \mathrm{rpm}$ $\left.u_{0}=1.65\right)$.

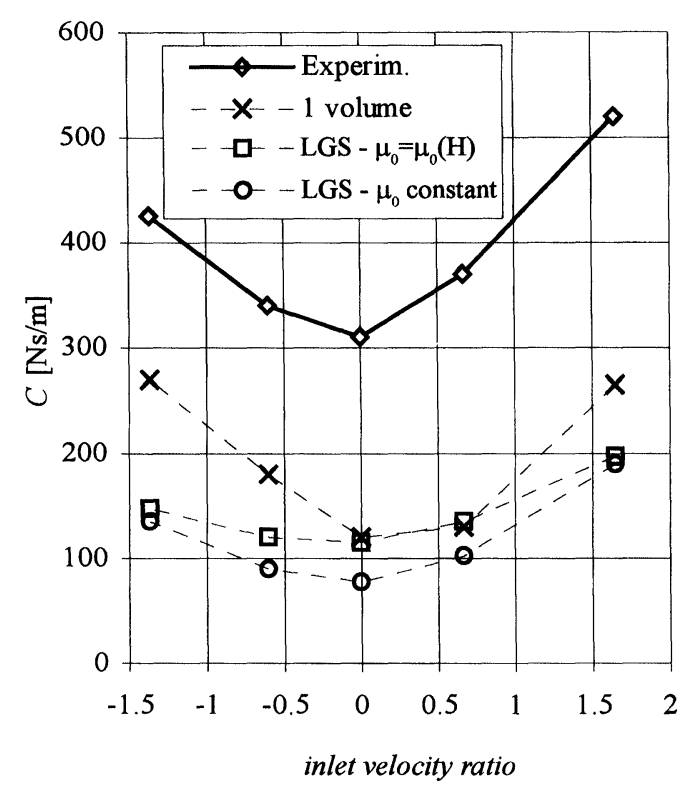

FIGURE 9 Direct damping for TOS seal (supply pressure $0.822 \mathrm{MPa}, 8000 \mathrm{rpm})$.

is incorrectly predicted. The influence of the difference in the kinetic carryover coefficient is high. The superiority of one model or the other is not always verified, depending on the operating range. 


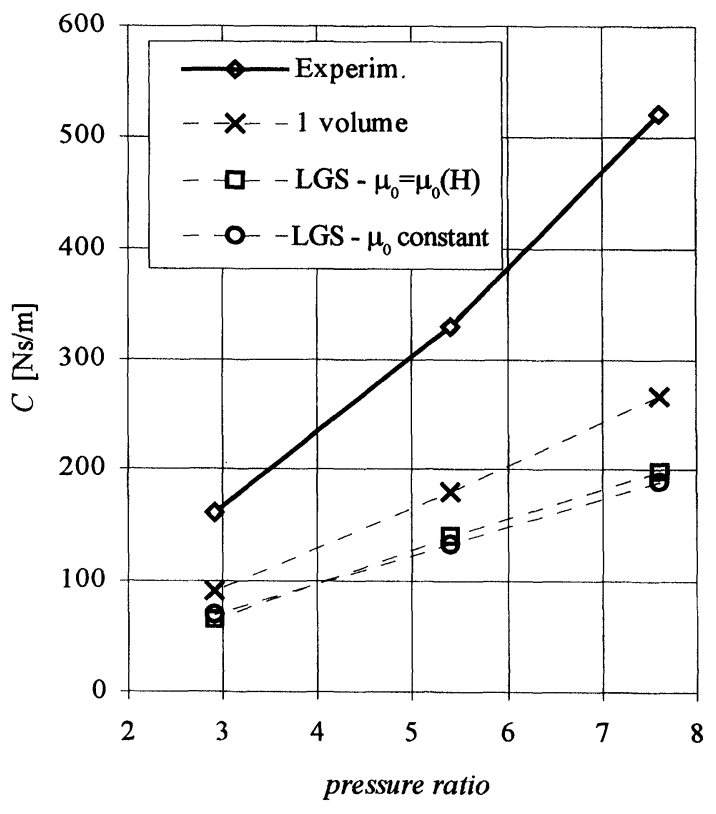

FIGURE 10 Direct damping for TOS seal $(8000 \mathrm{rpm}$ $\left.u_{0}=1.65\right)$

As far as damping coefficients are concerned, comparison with experimental coefficients is only indicative because of the experimental uncertainty. Figures 9 and 10 show theoretical and experimental direct damping coefficients for a TOS seal. Anyway the trend of the dependence on the operating quantities is correctly predicted by all models but the values are underestimated. The one-volume model seems to work better.

\section{MODIFICATIONS TO THE MODEL AND DISCUSSION OF RESULTS}

The attractiveness of the two-volume model due to its simplicity and low computing cost convinced the authors to analyze the model itself to find possible improvements. Some changes were made in order to test the sensitivity of the model to the error on the estimation of variables.

A first change was made to the expressions of shear stress in order to take into account the influence of curvature. A correction factor intro- duced by Schlichting (1979) is considered so that shear stress is given by

$$
\hat{\tau}_{\mathrm{r}}=\tau_{\mathrm{r}} \cdot\left[1.0+0.075 \cdot \mathrm{Re}_{1}^{0.25}\left(\mathrm{Dh}_{1} / r\right)^{0.5}\right] .
$$

In the diagrams the so-modified model is indicated as LGS-1.

The mean axial velocity considered in the problem is calculated from the leakage formula at the exit of the restriction. Although the dividing streamline makes a small angle with the assumed geometric boundary, taking as the first volume thickness its average thickness in the cavity, instead of its minimum one, yields an increase of thickness of about $10 \%$. In the diagrams the so-modified model is indicated as LGS-2.

Attention was also put on the expression of leakage. Scharrer's expression of the kinetic energy carryover coefficient yields a large error in the estimation of leakage in steady conditions but improves the evaluation of dynamic coefficients. The authors calculated leakage in steady conditions with the more accurate formula using it as the zeroth value in the perturbed equations and Scharrer's expression for defining perturbation terms. In the diagrams the so-modified model is called LGS-3.

Another difference introduced in the model is the perturbation of shear stress in the local clearance but it proved to have negligible influence.

The results of the changes described above are shown in Figs. 11-13, where the standard model is called LGS-0. Cross-coupled coefficients have not improved. LGS-1 has negligible influence, LGS-2 reduces the average discrepancy from experiment but makes the trend worse as the inlet velocity ratio changes, LGS-3 improves direct damping.

At this point some observations have to be made regarding the assumptions of the model. In dynamic conditions mean axial velocity in the first volume is derived from leakage and its perturbation while mass flow rate into the second volume should be considered as well. Another observation regards the determination of average axial velocity in the second volume, which is taken as a constant ratio of 


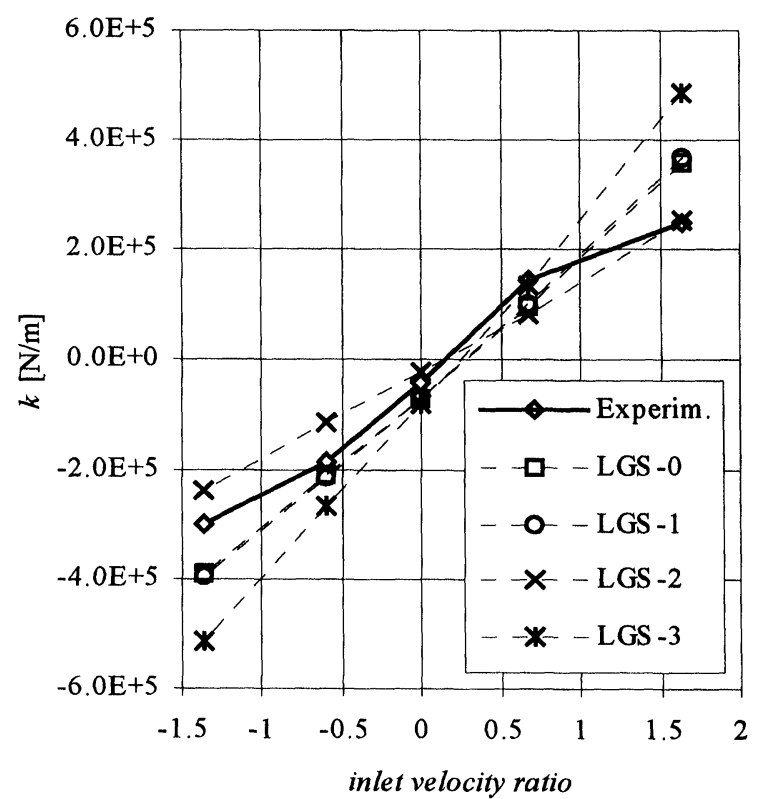

FIGURE 11 Cross-coupled stiffness for TOS seal (supply pressure $0.822 \mathrm{MPa}, 8000 \mathrm{rpm}$ ).

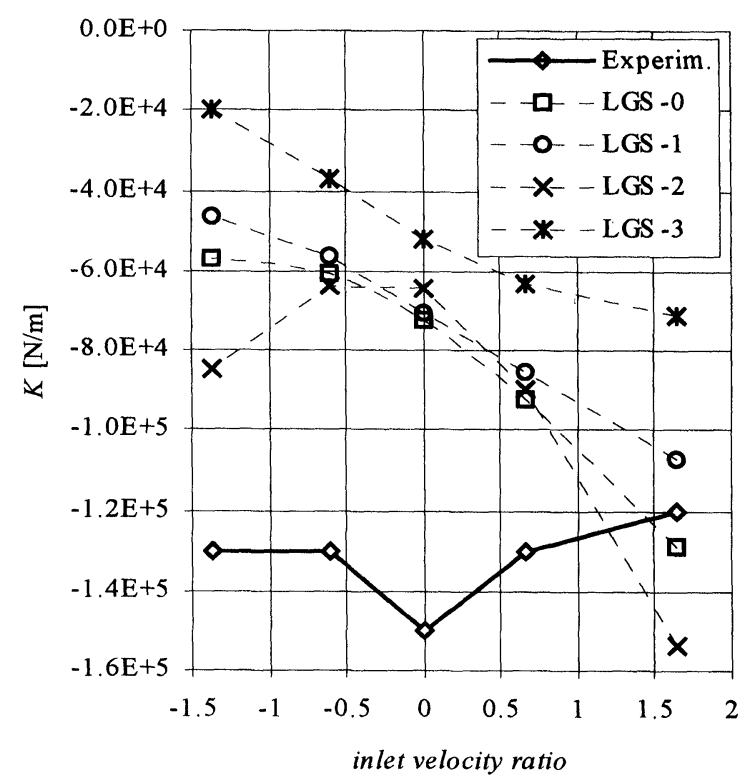

FIGURE 12 Direct stiffness for TOS seal (supply pressure $0.822 \mathrm{MPa}, 8000 \mathrm{rpm})$

that of the first volume. Both theoretical and CFD studies proving this relation are carried out in steady conditions, that is not considering rotor oscillating motion. Similarly the mixing length

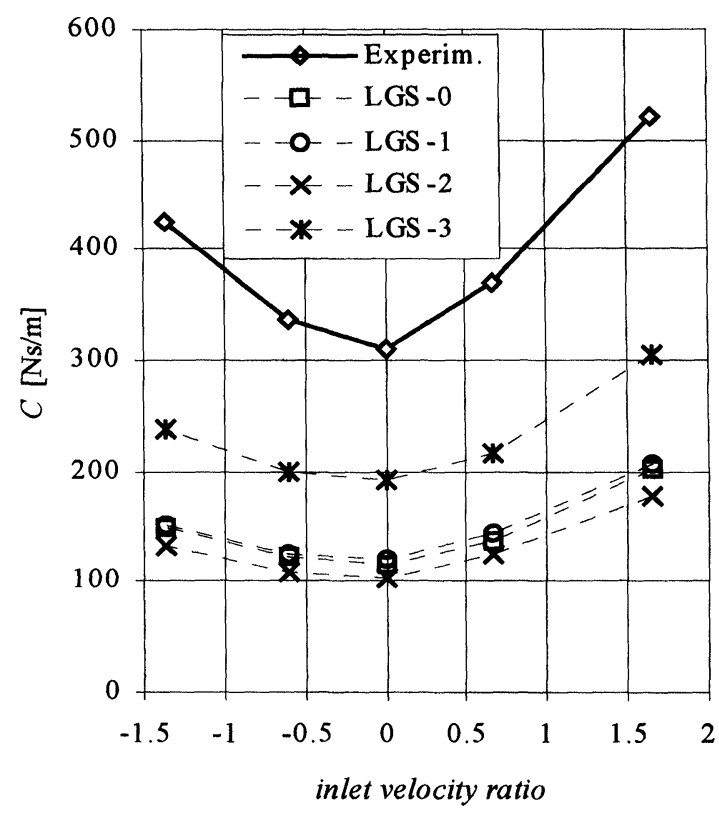

FIGURE 13 Direct damping for TOS seal (supply pressure $0.822 \mathrm{MPa}, 8000 \mathrm{rpm}$ )

ratio, used in the free shear stress equation, is considered to be constant and independent of cavity geometry. Even in that case the calculations were relative to steady conditions. Now both axial velocities and mixing length are fundamental parameters for calculating the shear stress between the two volumes which has a significant influence on the dynamic coefficients. In fact it is experimentally proved that stiffness and damping coefficients are quite sensitive to the circumferential velocity in the seal. A deeper analysis of this aspect will be object of future work, however the effect of the variation of the mixing length ratio on dynamic coefficients is shown. In Figs. 14 and 15 the coefficients are plotted for three values of the shear coefficient $\lambda(0.1,1,10$ times the original value $)$. Predicted cross-coupled stiffness improves for the lower value of the parameter while the trend of direct stiffness is poorly reproduced in all cases. Negligible difference is shown between the results corresponding to the higher values of $\lambda$. It is noteworthy that high values of the parameter imply high interaction between the two volumes, meaning 


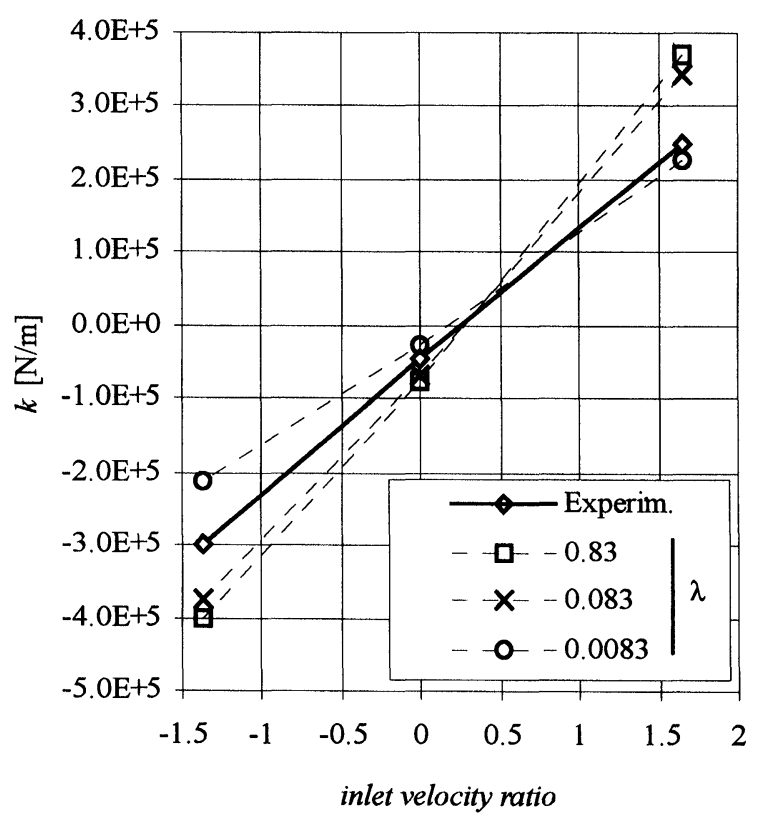

FIGURE 14 Cross-coupled stiffness for TOS seal (supply pressure $0.822 \mathrm{MPa}, 8000 \mathrm{rpm}$ ).

very close values of mean tangential velocities. In that case the two-volume model approaches the one-volume one.

\section{CONCLUSIONS}

A computer code based on a known two-volume model for the determination of labyrinth gas seal dynamic coefficients has been developed. The twovolume model proved to be better than the onevolume model in estimating cross-coupled stiffness in a significant range of operating conditions while no clear improvement was found for the other coefficients. The sensitivity of the model to a few variations was tested but none of the proposed changes was resolutive in improving the correlation of predicted and experimental coefficients. However the model proved to be more sensitive to those changes which affected axial velocity.

Therefore further investigation is necessary and more complex models have to be devised. Shear stress between the two volumes needs a more accurate definition and considering the uncertainty

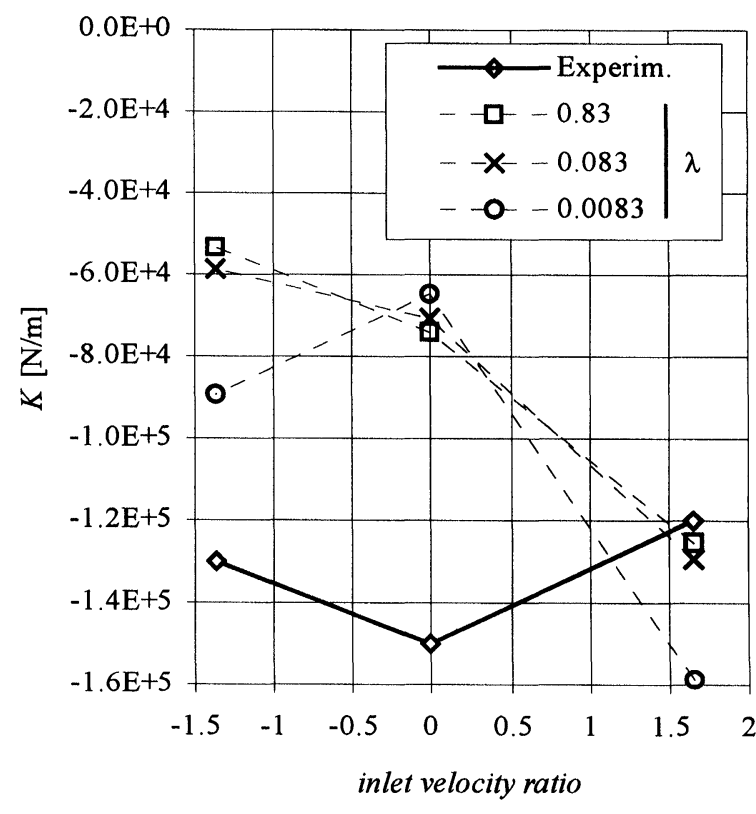

FIGURE 15 Direct stiffness for TOS seal (supply pressure $0.822 \mathrm{MPa}, 8000 \mathrm{rpm}$ ).

on its evaluation it might have a significant influence on results. Further CFD calculations are necessary in order to formulate relations between variables in dynamic conditions. Neglected effects such as temperature variations should also be investigated. Finally the need of new experimental results obtained in the operating ranges of practical interest is pointed out in order to make additional testing on the model.

\section{NOMENCLATURE}

$C, c \quad$ Direct and cross-coupled

$\mathrm{Cr} \quad$ Clearance

Dh Hydraulic diameter

F $\quad$ Force

$H \quad$ Local clearance

$K, k \quad$ Direct and cross-coupled stiffness coefficients

$L \quad$ Length

ND Number of teeth

$P \quad$ Pressure 


$\begin{array}{ll}R & \text { Gas constant } \\ \operatorname{Re} & \text { Reynolds number } \\ T & \text { Temperature } \\ U, W, V & \text { Circumferential, axial, total velocities } \\ X, Y & \text { Rectangular coordinates } \\ \dot{m} & \text { Mass flow rate } \\ r & \text { Journal radius } \\ \mathrm{td} & \text { Tooth width } \\ u_{0} & \text { Inlet velocity ratio } \\ \gamma & \text { Ratio of specific heats } \\ \varepsilon & \text { Eccentricity ratio } \\ \theta & \text { Angular coordinate } \\ \lambda & \text { Shear stress coefficient } \\ \mu_{0} & \text { Kinetic carryover coefficient } \\ & \text { Eqs. (3) and (4) } \\ \mu_{i} & \text { Flow coefficient, Eq. (2) } \\ \rho & \text { Density } \\ \tau & \text { Shear stress } \\ \omega & \text { Rotor angular speed }\end{array}$

\section{Subscripts}

$\begin{array}{ll}i & i \text {-th cavity } \\ j & \text { Free } \\ \mathrm{r}, \mathrm{s} & \text { Rotor, stator } \\ 1,2 & \text { Volume 1, volume 2 } \\ 0,1 & \text { Steady and perturbation }\end{array}$

\section{References}

Childs, D.W. (1993). Turbomachinery Rotordynamics, Wiley, New York, pp. 290-354
Childs, D.W. and Scharrer, J.K. (1986). Experimental rotordynamic coefficient results for teeth-on-rotor and teeth-onstator labyrinth gas seals, Journal of Engineering for Gas Turbines \& Power, 108, 599-604.

Childs, D.W. and Scharrer, J.K. (1988). Theory versus experiment for the rotordynamic coefficient of labyrinth gas seals: Part II - a comparison to experiment, Journal of Vibration, Acoustics, Stress, and Reliability in Design, Trans. ASME, 110, 281-287.

Iwatsubo, T. (1980). Evaluation of instability forces of labyrinth seals in turbines or compressors, Rotordynamic Instability Problems in High-Performance Turbomachinery, NASA CP2133, Proceedings of a Workshop held at Texas A\&M University, pp. 139-167

Iwatsubo, T., Matooka, N. and Kawai, R. (1982). Flow induced force and flow pattern of labyrinth seal, Rotordynamic Instability Problems in High-Performance Turbomachinery, NASA CP2250, Proceedings of a Workshop held at Texas A\&M University, pp. 205-222.

Neumann, K. (1964). Zur Frage der Verwendung von Durchblickdichtungen im Dampfturbinenbau, Maschinentechnik, 13(4).

Rhode, D.L. and Nail, G.H. (1992). Computation of cavity-bycavity flow development in generic labyrinth seals, Journal of Tribology, Trans. ASME, 114, 47-51.

Rhode, D.L., Hensel, S.J. and Guidry, M.J. (1993). Threedimensional computations of rotordynamic force distributions in a labyrinth seal, STLE Tribology Transactions, 36, 461-469.

Scharrer, J.K. (1988). Theory versus experiment for the rotordynamic coefficient of labyrinth gas seals: Part I - a two control volume model, Journal of Vibration, Acoustics, Stress, and Reliability in Design, Trans. ASME, 110 $270-280$.

Scharrer, J.K. (1985). A comparison of experimental and theoretical results for rotordynamic coefficients for labyrinth gas seals, Turbomachinery Laboratories Report, Texas A\&M University.

Schlichting, H. (1979). Boundary Layer Theory, McGraw-Hill, New York.

Wyssmann, H., Jenny, R. and Pham, T. (1984). Prediction of stiffness and damping coefficients for centrifugal compressor labyrinth seals, Journal of Engineering for Gas Turbines and Power, 106, 920-926. 


\section{ait \\ ENERGY MATERIALS}

M A N E Y publishing

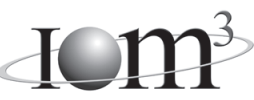

\section{Materials Science \& Engineering for Energy Systems}

Maney Publishing on behalf of the Institute of Materials, Minerals and Mining

The Institute of Materials, Minerals \& Mining

Economic and environmental factors are creating ever greater pressures for the efficient generation, transmission and use of energy. Materials developments are crucial to progress in all these areas: to innovation in design; to extending lifetime and maintenance intervals; and to successful operation in more demanding environments. Drawing together the broad community with interests in these areas, Energy Materials addresses materials needs in future energy generation, transmission, utilisation, conservation and storage. The journal covers thermal generation and gas turbines; renewable power (wind, wave, tidal, hydro, solar and geothermal); fuel cells (low and high temperature); materials issues relevant to biomass and biotechnology; nuclear power generation (fission and fusion); hydrogen generation and storage in the context of the 'hydrogen economy'; and the transmission and storage of the energy produced.

As well as publishing high-quality peer-reviewed research, Energy Materials promotes discussion of issues common to all sectors, through commissioned reviews and commentaries. The journal includes coverage of energy economics and policy, and broader social issues, since the political and legislative context influence research and investment decisions.

\section{CALL FOR PAPERS}

Contributions to the journal should be submitted online at http://ema.edmgr.com

To view the Notes for Contributors please visit: www.maney.co.uk/journals/notes/ema

Upon publication in 2006, this journal will be available via the Ingenta Connect journals service. To view free sample content online visit: www.ingentaconnect.com/content/maney

For further information please contact:

Maney Publishing UK

Tel: +44 (0)113 2497481 Fax: +44 (0)1132486983 Email: subscriptions@maney.co.uk

or

Maney Publishing North America

Tel (toll free): 8662975154 Fax: 6173546875 Email: maney@maneyusa.com

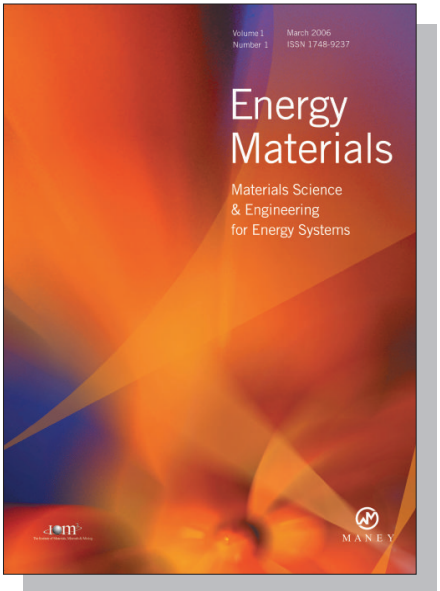

EDITORS

Dr Fujio Abe

NIMS, Japan

Dr John Hald, IPL-MPT, Technical University of Denmark, Denmark

Dr R Viswanathan, EPRI, USA

\section{SUBSCRIPTION INFORMATION}

Volume 1 (2006), 4 issues per year

Print ISSN: 1748-9237 Online ISSN: 1748-9245

Individual rate: $£ 76.00 / U S \$ 141.00$

Institutional rate: $£ 235.00 /$ US $\$ 435.00$

Online-only institutional rate: $£ 199.00 / U S \$ 367.00$

For special $\mathrm{IOM}^{3}$ member rates please email

subscriptions@maney.co.uk

\section{For further information or to subscribe online please visit www.maney.co.uk}



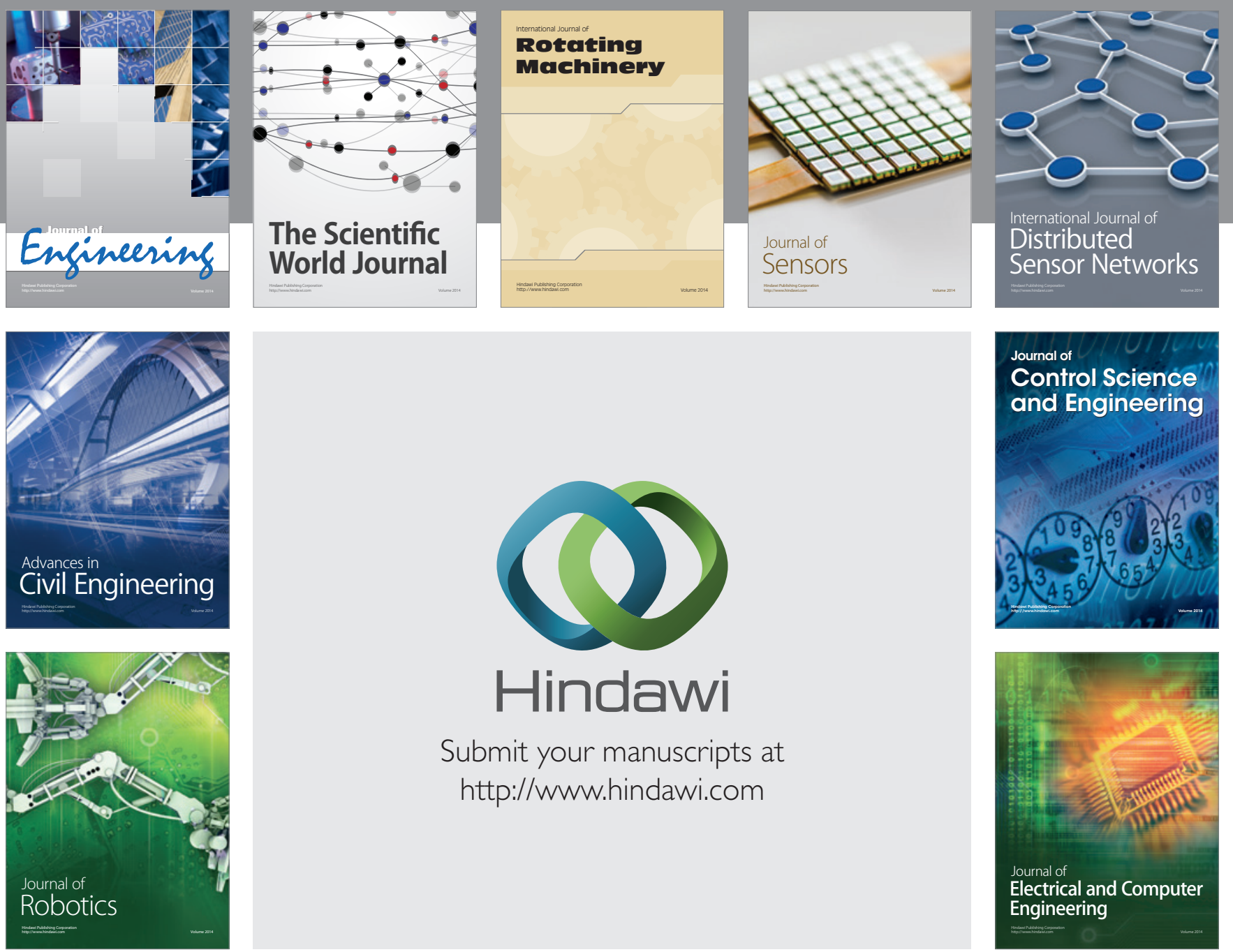

Submit your manuscripts at

http://www.hindawi.com
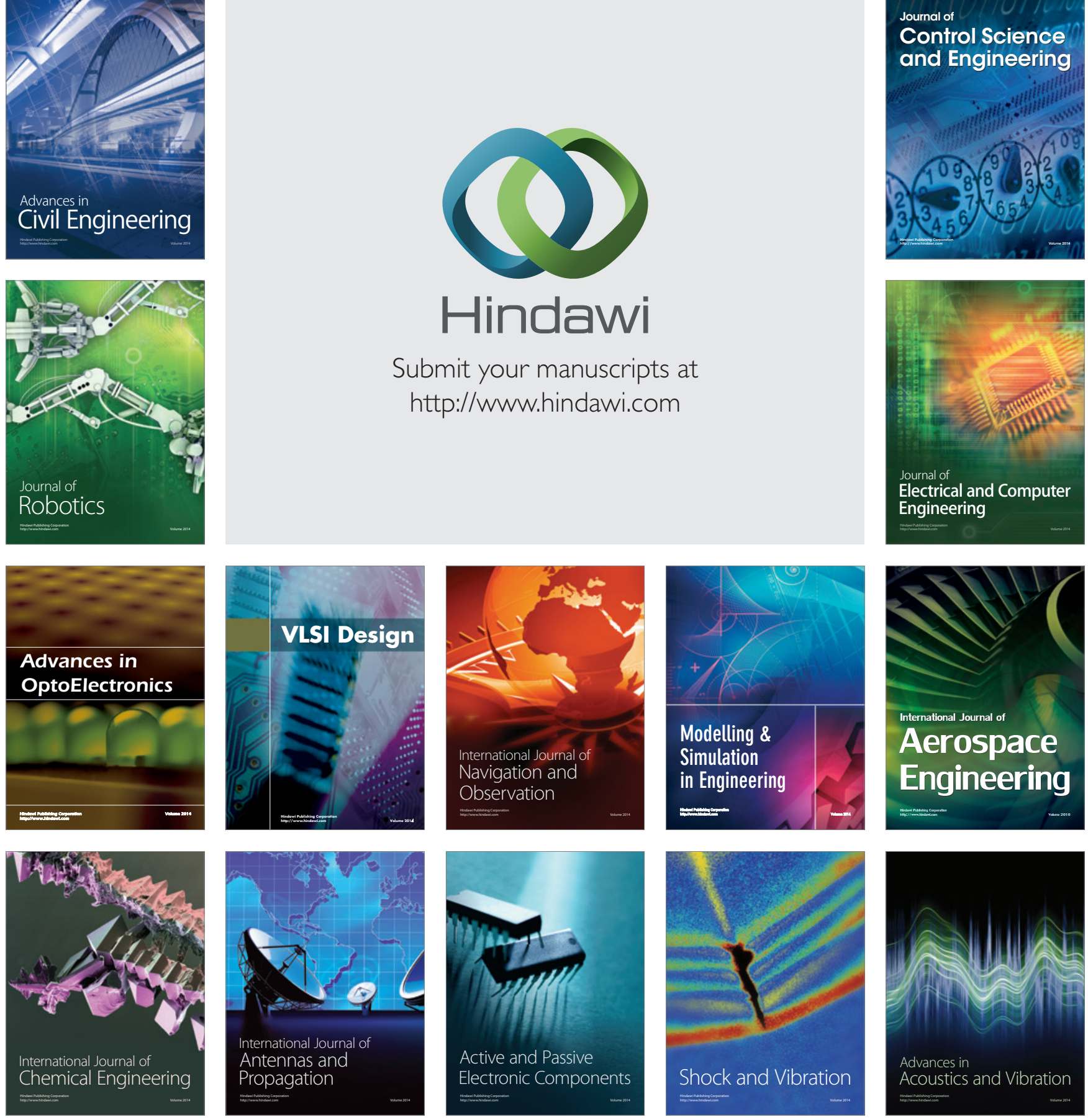